\title{
The effect of resistant hypertension on in-hospital mortality in patients hospitalized with COVID-19
}

\author{
Ferhat Ișık (iD ${ }^{1 凶}$, Murat Çap ${ }^{1}$, Abdurrahman Akyüz ${ }^{1}$, Önder Bilge ${ }^{1}$, Burhan Aslan ${ }^{1}$, Ümit İnci ${ }^{1}$, İlyas Kaya ${ }^{1}$, Ercan Taștan ${ }^{1}$, Metin Okșul ${ }^{1}$, \\ Neșe Kanbal Çap ${ }^{2}$, Ali Karagöz ${ }^{3}$ and Erkan Baysal ${ }^{1}$
}

(c) The Author(s), under exclusive licence to Springer Nature Limited 2021

\begin{abstract}
Hypertension is a major concomitant disease in hospitalized patients with COVID-19 (Coronavirus disease 2019) infection. The adverse effect of hypertension on prognosis in COVID-19 is known. Nevertheless, it is not known how COVID-19 progresses in resistant hypertensive patients. In this study, we aimed to examine the effect of resistant hypertension (ResHT) on in-hospital mortality in patients hospitalized with COVID-19. In our single-center retrospective study, included 1897 COVID-19 patients. The patients were divided into three groups according to the non-hypertensive $(n=1211)$, regulated HT (RegHT) $(n=574)$, and ResHT $(n=112)$. These three groups were compared according to demographic features, clinical signs, laboratory findings, and follow-up times. The median age of the study population was 62 (50-72 IQR) and 1000 (52.7\%) of patients were male. The total mortality of the study population was $18.7 \%(n=356)$. Mortality rates were similar in the hypertensive patient group ( $27.5 \%$ for the RegHT and $32.1 \%$ for ResHT, $p=0.321$ ). In a multivariable analysis, ResHT was independently associated with a significantly increased risk of inhospital mortality of COVID-19, while no significant increased risk was observed with RegHT [respectively, Odds Ratio (OR) $=2.013$, Confidence Interval (Cl) 1.085-3.734, $p=0.026$ and $\mathrm{OR}=1.194, \mathrm{Cl} 0.795-1.794, p=0.394]$. Also, age, male gender, chronic renal failure, lymphocyte, procalcitonin, creatinine, and admission SpO2 levels were determined as independent predictors of in-hospital mortality. In our study, it was found that ResHT was an independent predictor of mortality in patients hospitalized with COVID-19; however, this situation was not found in RegHT.
\end{abstract}

Journal of Human Hypertension (2022) 36:846-851; https://doi.org/10.1038/s41371-021-00591-8

\section{INTRODUCTION}

The coronavirus disease 2019 (COVID-19) outbreak continues as a global problem all over the world. Recent data has shown that $>100$ million people worldwide have been infected and $>2$ million have died [1]. COVID-19 has a large spectrum of clinical effects, from asymptomatic carriage to death. Common symptoms include fever, fatigue, myalgia, dyspnea, and dry cough. Most COVID-19 patients show mild or no symptoms but some patients may develop severe pneumonia with progression to fatal complications, including acute respiratory distress syndrome (ARDS), multiorgan failure, and death. Undesirable conditions such as intensive care need, respiratory failure, ARDS, and in-hospital death are more common with the increasing of comorbidity. Hypertension is the most common comorbidity in hospitalized COVID-19 patients $[2,3]$. Although it is known that hypertension adversely affects the prognosis in COVID-19 patients, the mechanism of exacerbation associated with underlying causes remains obscure.

Resistant hypertension (ResHT) is defined as high blood pressure (BP) $(\geq 130 / 80 \mathrm{mmHg})$ in a patient despite the concurrent use of 3 antihypertensive drug classes, commonly including a calcium channel blocker, a blocker of the renin-angiotensinaldosterone system (angiotensin-converting enzyme inhibitor or angiotensin receptor blocker), and a diuretic. ResHT also includes patients whose BP achieves target values $(<130 / 80 \mathrm{mmHg}) 4$ or more antihypertensive drugs [4, 5]. Epidemiologic studies report a highly variable prevalence for ResHT that ranges between $2 \%$ and $40 \%$ depending on how ResHT was defined [6]. The adverse clinical outcomes, cardiovascular events, and all-cause mortality are seen at a higher rate in $\operatorname{ResHT}$ than in $\operatorname{RegHT}[7,8]$. Hypertension has been observed to increase the disease severity and risk of mortality in COVID-19 patients [9]. It is not known how COVID-19 progresses in resistant hypertensive patients. Because there is no study on the effect of ResHT on in-hospital mortality. In this study, we aimed to examine the effect of ResHT on in-hospital mortality in patients hospitalized due to COVID-19.

\section{MATERIAL AND METHODS}

Our study was designed as a single-center, retrospective, and observational study. Within the scope of our study, data obtained from 3144 COVID-19 patients who have been hospitalized at the Diyarbakır Gazi Yaşargil Training and Research Hospital between 1 August 2020 and 30 November 2020, were screened. Combined oral and nasopharyngeal swab samples and thorax CT (computerized tomography) of each patient were examined. Nine hundred eighty-six patients whose two PCR (polymerase chain reaction) tests were negative were excluded. Two thousand one hundred fifty-eight patients with positive PCR tests were included in the study. Patients with or without known hypertension whose average BP at admission was $\geq 130 / 80 \mathrm{mmHg}$ and who did not use any antihypertensive

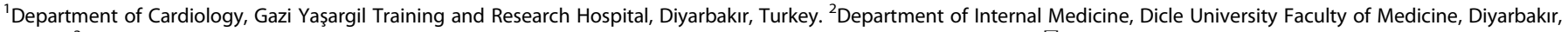
Turkey. ${ }^{3}$ Department of Cardiology, Kartal Koşuyolu Yüksek İhtisas Training and Research Hospital, İstanbul, Turkey. ${ }^{凶}$ email: frht_0316@hotmail.com 


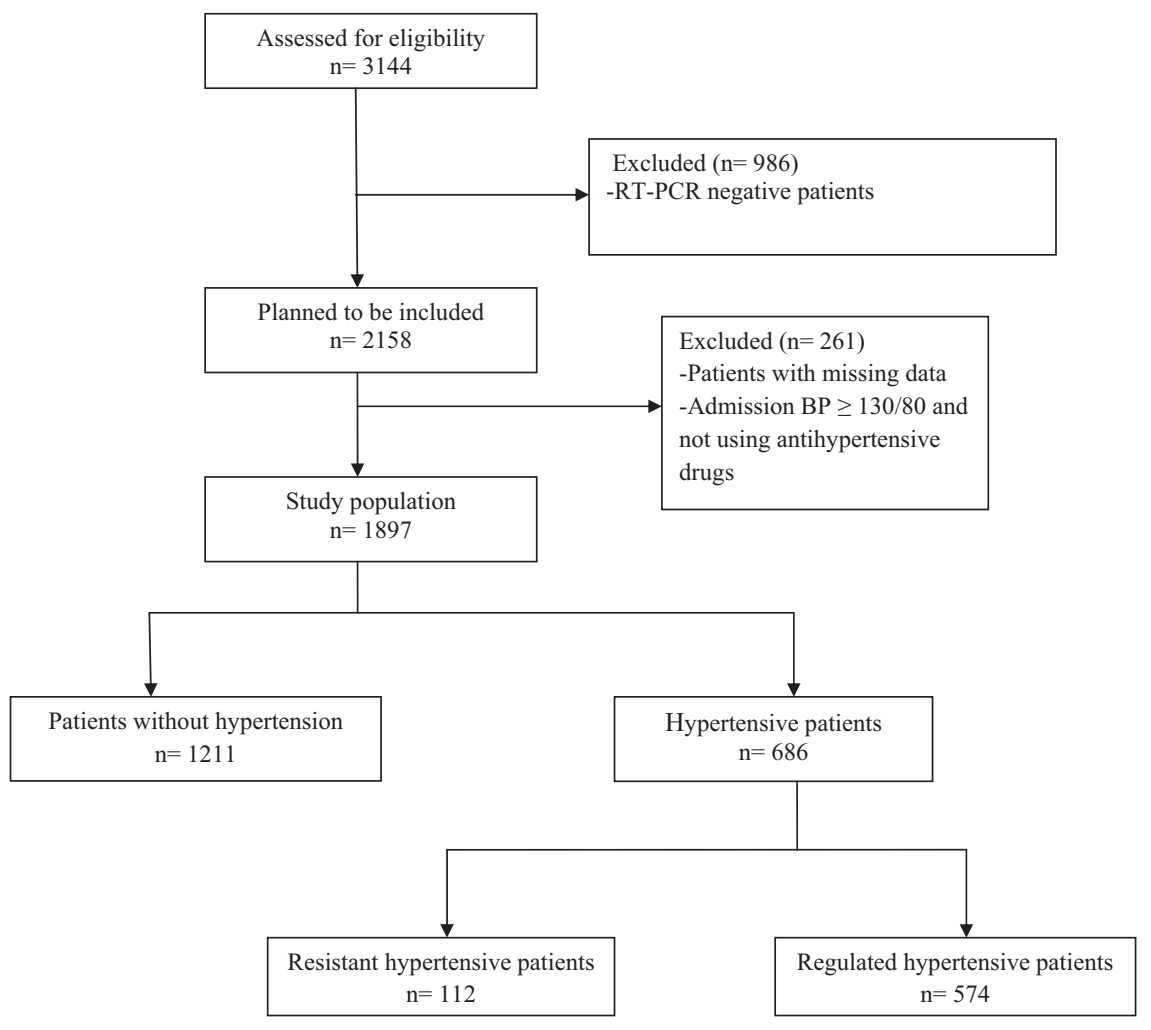

Fig. 1 Flow-chart of patient selection.

drugs $(n=52)$ and patients with missing data $(n=209)$ were excluded. After exclusion criteria, the remaining 1897 patients were divided into nonhypertensive, RegHT, and ResHT groups (Fig. 1). Demographic features, clinical signs, laboratory findings, and follow-up times were examined from our hospital's database. BP values for all patients on the day of admission were examined. Except for the BP value measured at admission, the average of the BP values measured on the first day of each hospitalized patient was taken (average of four measurements for non-hypertensive patients, average of ten measurements for hypertensive patients). Initial BP measurements were not taken to exclude the "white coat effect". Despite the optimal use of three antihypertensive drugs one of which is a diuretic, including RAAS (renin-angiotensin-aldosterone system) blocker and calcium channel blocker, $B P \geq 130 / 80 \mathrm{mmHg}$ or reaching the target BP $(<130 / 80 \mathrm{mmHg})$ with antihypertensive drugs 4 and more was considered as ResHT. The antihypertensive drugs used by the patients were detected from the Ministry of Health database. These drugs were ordered from admission in-hospital. The diagnosis, classification, and treatment of COVID-19 infection followed the guidelines of the Republic of Turkey Ministry of Health, COVID-19 guide [10]. The thorax CT and severity of hypoxemia were used for ARDS diagnosis. Mortality was identified as an adverse outcome. Our application to register our study as a Ministry of Health Scientific Research was approved, which was followed by the approval of the ethics committee of our hospital.

\section{Statistical analysis}

The analysis of the data was carried out using SPSS (Statistical Package for Social Science for Windows)-24 packaged software. The continuous variables were presented as a median interquartile range (IQR) (25-75\%) owing to their non-normal distribution. The histogram and Shapiro-Wilks test were used to verify the normal distribution of data. The categorical variables were expressed as percentages. Chi-square test was used to compare categorical variables between groups. Continuous variables were compared by Kruskal-Wallis $\mathrm{H}$ test and Mann-Whitney $\mathrm{U}$ test. The univariate and multivariate logistic regression analyses were performed to determine the predictors of in-hospital mortality. Variables with $p<0.2$ were added to the model in multivariate analysis. There must be ideally $10-20$ participants having the primary outcome per candidate predictor variables [11]. Our model had 23 predictors and 356 in-hospital mortality (Event per variable $356 / 23=15.5$ ). We selected predictive candidates based on previous studies and known or plausible associations with exposure to COVID-19 infection [12]. When included regression model, logarithmic transformation was applied for continuous variables with high variance; lactate dehydrogenase, $\mathrm{d}$-dimer, ferritin, procalcitonin, C-reactive protein. Standardized $\beta$ coefficients and $95 \%$ confidence intervals $(\mathrm{Cl})$ were calculated. The statistical significance level of the obtained data was interpreted with the " $p$ " value. Values of $p<$ 0.05 were considered to be statistically significant. In subgroup analysis (between RegHT and ResHT group), the $p$ value was adjusted to 0.025 .

\section{RESULT}

One thousand eight hundred ninety-seven patients were included in the study. The median age of the study population was 62 (50-72 IQR) and 1000 (52.7\%) of patients were male. Hypertension was observed in $36.1 \%(n=686)$ of the study population and total mortality was $18.7 \%(n=356)$. The patients were divided into three groups according to the non-hypertensive $(n=1211)$, $\operatorname{RegHT}(n=574)$, and ResHT $(n=112)$. Mortality, ICU (intensive care unit) need, and ARDS were higher in RegHT and ResHT groups compared to the non-HT group $(p<0.001)$. The baseline characteristics, clinical and laboratory findings of the nonhypertensive, regulated, and resistant groups are presented comparatively in Table 1.

RegHT and ResHT groups were compared with each other. Systolic BP $(p<0.001)$, diastolic BP $(p<0.001)$, CAD ratio $(p=0.002)$, CHF ratio $(p=0.001)$, use of antihypertensive drugs (except alpha blocker) were higher in the ResHT. Aspartate transaminase $(p=0.024)$ and ferritin levels $(p=0.015)$ were higher in the regulated group. ICU need, ARDS, and mortality rates were similar in both groups. Demographic, laboratory, and clinical features of the two groups are presented comparatively in Table 2.

In a multivariable analysis, ResHT was independently associated with a significantly increased risk of in-hospital mortality of COVID-19, while no significant increased risk was observed with RegHT [respectively, Odds Ratio $(\mathrm{OR})=2.013$, Confidence Interval (Cl) 1.085-3.734, $p=0.026$; OR $=1.194, \mathrm{Cl} 0.795-1.794$, 
Table 1. Demographic characteristics, clinical and laboratory finding of patients.

\begin{tabular}{|c|c|c|c|c|c|}
\hline Variables & $\begin{array}{l}\text { All patients } \\
(n=1897)\end{array}$ & $\begin{array}{l}\text { Non-hypertensive patients } \\
(n=1211)\end{array}$ & $\begin{array}{l}\text { Regulated HT } \\
(n=574)\end{array}$ & $\begin{array}{l}\text { Resistant HT } \\
(n=112)\end{array}$ & $p$ value \\
\hline Systolic BP, mmHg & $113(110-120)$ & $110(110-120)$ & $120(110-130)$ & $130(120-137)$ & $<0.001$ \\
\hline Male gender, $n$ (\%) & $1000(52.7)$ & $716(59.1)$ & $245(42.6)$ & $39(34.8)$ & $<0.001$ \\
\hline CAD, $n(\%)$ & $260(13.7)$ & $73(6.0)$ & $143(24.9)$ & $44(39.3)$ & $<0.001$ \\
\hline COPD, $n(\%)$ & $130(6.8)$ & $64(5.3)$ & $56(9.7)$ & $10(10.7)$ & 0.002 \\
\hline Stroke, $n(\%)$ & $80(4.2)$ & $21(1.7)$ & $43(7.5)$ & $16(14.2)$ & $<0.001$ \\
\hline CRF, $n(\%)$ & $79(4.1)$ & $22(1.8)$ & $48(8.3)$ & $9(8.0)$ & $<0.001$ \\
\hline Atrial fibrillation, $n(\%)$ & $62(3.3)$ & $17(1.4)$ & $38(6.6)$ & $7(6.2)$ & $<0.001$ \\
\hline Malignancy, $n$ (\%) & $37(2.0)$ & $16(1.3)$ & $16(2.8)$ & $5(4.5)$ & 0.016 \\
\hline Calcium, mg/dL & $8.2(7.9-8.7)$ & $8.2(7.9-8.6)$ & $8.2(7.9-8.7)$ & $8.4(7.9-8.8)$ & 0.349 \\
\hline C-reactive protein, $\mathrm{mg} / \mathrm{dL}$ & $74.5(34.8-124.0)$ & $73.1(34.0-119.0)$ & $77.0(36.0-128.1)$ & 86.6 (35.4-137.8) & 0.106 \\
\hline AST, IU/L & $32(23-47)$ & $34(24-50)$ & $31(23-43)$ & $27(22-36)$ & $<0.001$ \\
\hline ALT, IU/L & $25(17-40)$ & $27(18-47)$ & $23(16-34)$ & $20(15-28)$ & $<0.001$ \\
\hline $\mathrm{LDH}, \mathrm{IU} / \mathrm{L}$ & $325(256-421)$ & $325(257-425)$ & $323(255-417)$ & $322(253-419)$ & 0.977 \\
\hline Ferritin, ng/ml & $427(216-829)$ & $460(225-892)$ & $396(212-731)$ & $292(148-592)$ & 0.002 \\
\hline D-Dimer, ng/ml & $254(171-424)$ & $242(167-404)$ & $275(182-462)$ & $282(175-424)$ & 0.007 \\
\hline Procalcitonin, $\mathrm{ng} / \mathrm{ml}$ & $0.10(0.05-0.21)$ & $0.09(0.05-0.19)$ & $0.11(0.06-0.28)$ & $0.14(0.06-0.37)$ & $<0.001$ \\
\hline Troponin, ng/ml & $0.10(0.10-0.10)$ & $0.10(0.10-0.10)$ & $0.10(0.10-0.10)$ & $0.10(0.10-0.10)$ & $<0.001$ \\
\hline WBC, $10^{9} / \mathrm{L}$ & $6.87(5.14-9.55)$ & $6.59(5.03-9.45)$ & $7.16(5.31-9.67)$ & $7.23(5.45-10.43)$ & 0.025 \\
\hline Dyspnea, $n(\%)$ & $1357(71.5)$ & $870(71.8)$ & $406(70.7)$ & $81(72.3)$ & 0.896 \\
\hline Cough, $n(\%)$ & $808(42.6)$ & $543(44.8)$ & $221(38.5)$ & $44(39.3)$ & 0.031 \\
\hline Weakness, $n$ (\%) & $1088(57.3)$ & 769 (63.5) & $275(47.9)$ & $44(39.2)$ & $<0.001$ \\
\hline Admission $\mathrm{SO} 2 \%$ & $90(85-93)$ & $90(86-94)$ & $88(82-91)$ & $87(82-90)$ & $<0.001$ \\
\hline Nasal O2 giving, $n(\%)$ & $1254(63.1)$ & $728(60.1)$ & $436(75.9)$ & $90(80.4)$ & $<0.001$ \\
\hline Need for NIMV, $n$ (\%) & $290(15.2)$ & $142(11.7)$ & $122(21.2)$ & $26(23.2)$ & $<0.001$ \\
\hline Need for MV, $n$ (\%) & $310(16.3)$ & $152(12.5)$ & $135(23.5)$ & $23(20.5)$ & $<0.001$ \\
\hline Need for ICU, $n(\%)$ & $490(25.8)$ & $240(19.8)$ & $211(36.7)$ & $39(34.8)$ & $<0.001$ \\
\hline ARDS, $n(\%)$ & $262(13.8)$ & $97(8.0)$ & $133(23.1)$ & $32(28.5)$ & $<0.001$ \\
\hline Hospitalization time, day & $8(6-12)$ & $7(6-11)$ & $9(6-12)$ & $9(7-12)$ & 0.001 \\
\hline Death, $n$ (\%) & $356(18.7)$ & $162(13.3)$ & $158(27.5)$ & $36(32.1)$ & $<0.001$ \\
\hline
\end{tabular}

Data are expressed as median interquartile range and count (percentage).

$A L T$ alanine transaminase, ARDS acute respiratory distress syndrome, AST aspartate transaminase, BP blood pressure, CAD coronary artery disease, CHF chronic heart failure, $C O P D$ chronic obstructive pulmonary disease, $C R F$ chronic renal failure, $H T$ hypertension, ICU intensive care unit, $L D H$ lactate dehydrogenase, $M V$ mechanical ventilation, NIMV noninvasive mechanical ventilation, NLR neutrophil/lymphocyte ratio, SO2 oxygen saturation, WBC white blood cell.

$p=0.394$ ]. Also, age (OR: $1.052, \mathrm{Cl}: 1.036-1.069, p<0.001)$, male gender (OR:1.569, Cl: 1.063-2.316, $p=0.023$ ), chronic renal failure (OR: $3.680, \mathrm{Cl}: 1.081-12.523, p=0.037$ ), lymphocyte level (OR: $0.677, \mathrm{Cl}: 0.473-0.971, p=0.034$ ), procalcitonin level (OR:
2.034, Cl: 1.489-2.779, $p<0.001$ ), creatinin level (OR: $1.222, \mathrm{Cl}:$ 1.014-1.473, $p=0.035$ ), and admission SpO2 levels (OR: 0.822, $\mathrm{Cl}: 0.799-0.846, p<0.001)$ were determined as independent predictors of in-hospital mortality (Table 3 ). 
Table 2. Demographic, laboratory, and clinical features in regulated $\mathrm{HT}$ and resistant $\mathrm{HT}$ groups.

\begin{tabular}{|c|c|c|c|}
\hline Variables & $\begin{array}{l}\text { Regulated HT } \\
(n=574)\end{array}$ & $\begin{array}{l}\text { Resistant HT } \\
(n=112)\end{array}$ & $p$ value \\
\hline Age, years & $68(60-77)$ & $70(62-75)$ & 0.544 \\
\hline Gender, female, $n(\%)$ & $329(57.3)$ & $73(65.1)$ & 0.122 \\
\hline Systolic BP, mmHg & $120(110-130)$ & $130(120-137)$ & $<0.001$ \\
\hline Diastolic BP, mmHg & $70(70-80)$ & $80(70-80)$ & $<0.001$ \\
\hline CAD, $n(\%)$ & $143(24.9)$ & $44(39.3)$ & 0.002 \\
\hline $\mathrm{CHF}, n(\%)$ & $22(3.8)$ & $11(9.8)$ & 0.001 \\
\hline $\begin{array}{l}\text { Diabetes mellitus, } \\
n(\%)\end{array}$ & $230(40.0)$ & $40(35.7)$ & 0.388 \\
\hline COPD, $n(\%)$ & $56(9.7)$ & $10(10.7)$ & 0.983 \\
\hline Stroke, $n(\%)$ & $43(7.5)$ & $16(14.2)$ & 0.019 \\
\hline CRF, $n(\%)$ & $48(8.3)$ & $9(8.0)$ & 0.862 \\
\hline Atrial fibrillation, $n$ (\%) & $38(6.6)$ & $7(6.2)$ & 0.618 \\
\hline \multicolumn{4}{|c|}{ Antihypertensive drugs, $n$ (\%) } \\
\hline RAAS blockers & $462(80.4)$ & $109(97.3)$ & $<0.001$ \\
\hline MRA & $9(1.6)$ & $14(12.5)$ & $<0.001$ \\
\hline Thiazide or indapamide & $262(45.6)$ & $111(99.1)$ & $<0.001$ \\
\hline Calcium antagonists & $259(45.1)$ & $105(93.7)$ & $<0.001$ \\
\hline Beta blocker & $210(36.6)$ & $72(64.3)$ & $<0.001$ \\
\hline Alpha blocker & $25(4.3)$ & $7(6.2)$ & 0.384 \\
\hline Creatinine, $\mathrm{mg} / \mathrm{dL}$ & $1.06(0.82-1.50)$ & $1.07(0.88-1.47)$ & 0.236 \\
\hline $\begin{array}{l}\text { C-reactive protein, } \\
\mathrm{mg} / \mathrm{dL}\end{array}$ & $77.0(36.0-128.1)$ & $86.6(35.4-137.8)$ & 0.642 \\
\hline Sodium, meq/L & $136(133-138)$ & $136(133-138)$ & 0.804 \\
\hline AST, IU/L & $31(23-43)$ & $27(22-36)$ & 0.024 \\
\hline ALT, IU/L & $23(16-34)$ & $20(15-28)$ & 0.041 \\
\hline WBC, $10^{9} / \mathrm{L}$ & $7.16(5.31-9.67)$ & $7.23(5.45-10.43)$ & 0.848 \\
\hline Hemoglobin, gr/dL & $13.2(11.9-14.3)$ & $12.9(11.8-14.0)$ & 0.203 \\
\hline NLR & 5.27 (3.19-9.04) & $5.54(3.42-8.90)$ & 0.873 \\
\hline Ferritin, ng/ml & $396(212-731)$ & $292(148-592)$ & 0.015 \\
\hline D-Dimer, ng/ml & $275(182-462)$ & $282(175-424)$ & 0.895 \\
\hline Procalcitonin, ng/ml & $0.11(0.06-0.28)$ & $0.14(0.06-0.37)$ & 0.362 \\
\hline Troponin, ng/ml & $0.10(0.10-0.10)$ & $0.10(0.10-0.10)$ & 0.088 \\
\hline Admission $\mathrm{SO} 2 \%$ & $88(82-91)$ & $87(82-90)$ & 0.398 \\
\hline $\begin{array}{l}\text { Total hospitalization } \\
\text { time, day }\end{array}$ & $9(6-12)$ & $9(7-12)$ & 0.595 \\
\hline Nasal $\mathrm{O} 2$ giving, $n$ (\%) & $436(75.9)$ & $90(80.4)$ & 0.314 \\
\hline Need for ICU, $n$ (\%) & $211(36.7)$ & $39(34.8)$ & 0.569 \\
\hline NIMV follow-up, $n$ (\%) & $122(21.2)$ & $26(23.2)$ & 0.801 \\
\hline MV follow-up, $n(\%)$ & $135(23.5)$ & $23(20.5)$ & 0.136 \\
\hline ARDS, $n(\%)$ & $133(23.1)$ & $32(28.5)$ & 0.225 \\
\hline Exitus, $n(\%)$ & $158(27.5)$ & $36(32.1)$ & 0.321 \\
\hline
\end{tabular}

In this table significance of $p$ value set 0.025 because of the subgroup of data. Data are expressed as median interquartile range and count (percentage).

$A L T$ alanine transaminase, ARDS acute respiratory distress syndrome, $A S T$ aspartate transaminase, $B P$ blood pressure, $C A D$ coronary artery disease, $C H F$ chronic heart failure, $C O P D$ chronic obstructive pulmonary disease, $C R F$ chronic renal failure, $H T$ hypertension, ICU intensive care unit, MRA mineralocorticoid receptor antagonists, $M V$ mechanical ventilation, NIMV noninvasive mechanical ventilation, NLR neutrophil/lymphocyte ratio, RAAS renin-angiotensin-aldosterone system, SO2 oxygen saturation, WBC white blood cell.

\section{DISCUSSION}

Previous studies have examined the relationship between COVID19 and hypertension. To the best of our knowledge, this study is the first to evaluate resistant hypertensive patients hospitalized with COVID-19. The intensive care need, ARDS, and mortality were significantly different between the three groups, and these rates were observed more in the RegHT and ResHT group than in the non-hypertensive patient group. Besides, the ResHT is an independent predictor of mortality in COVID-19 patients. The outcomes provide substantial proof for the practical management of COVID-19 patients with ResHT.

Recent findings showed that hypertension represented one of the most common comorbidities in patients hospitalized with COVID-19. The prevalence of hypertension is different according to studies and regions. In a study conducted in China, this rate varied between $16.9 \%$ and $31.2 \%$, while it was seen $49 \%$ in Lombardy of Italy and $56.6 \%$ in New York USA [2, 3, 13]. In our study, the prevalence of hypertension was $36.1 \%$ in patients with hospitalized COVID-19. Hypertension is known to be associated with increased mortality in COVID-19 patients. Also, hypertension is associated with a higher risk of all-cause mortality from other comorbidities, regardless of gender and age [14]. The mechanisms by which hypertension results in the poor clinical outcome of COVID- 19 remain unclear [15]. One of the most known hypotheses is the overexpression of angiotensin-converting enzyme II (ACE 2) in arterial endothelial and smooth muscle cells [16]. But there is no satisfactory practical or clinical evidence that this condition worsens the disease. Clinicians have proposed an in-depth analysis of BP control in hypertension patients during the clinical course of COVID-19 [17].

Data on the effect of hypertension subgroups (for example uncontrolled HT or resistant HT) on COVID-19 prognosis is insufficient. It is obscure whether uncontrolled BP is a risk factor for COVID-19 disease, or whether controlled BP patients with hypertension is or is not less of a risk factor. Nevertheless, some references have stressed the fact that BP control remains an important consideration to reduce disease burden, even if it has no effect on susceptibility to the COVID-19 infection [18]. The association of ResHT with adverse clinical outcomes is known. ResHT causes target-organ damage, microvascular and macrovascular damage [19]. In a population-based cohort study, ResHT was found to increase the risk of coronary heart disease and cerebrovascular disease. Also, it has been shown that ResHT is associated with all-cause mortality [20]. ResHT causes macrovascular and microvascular end-organ (target-organ) damage, leading to adverse clinical outcomes. Macrovascular damage is caused by vascular calcification and arterial stiffness in large vessels. Carotid intima-media thickness increases, plaques occur in the aorta, and peripheral arterial diseases are seen [19]. Microvascular damage occurs by remodeling of small arteries. The size of remodeling is associated with worse prognosis. It was observed that the media/lumen ratio (index of eutrophic remodeling) increased in tissue samples taken from small arteries [21]. Microalbuminuria is another vascular complication of ResHT and is an early biomarker. It shows intrarenal vascular dysfunction [19]. Cerebral microangiopathy is a vasculopathy in patients with long-term ResHT. Systolic BP and signs of hypertensive vasculopathy such as peripheral and central pulse pressure and pulse wave velocity were associated with cerebral microangiopathy in patients with long-standing ResHT [22]. There is a growing view that serious COVID-19 disease causes significant vascular abnormalities, including common microthrombotic and macrothrombotic events, renal and heart failure. COVID-19 is known to cause multisystemic involvement by creating endothelial dysfunction, vasculitis, and circulatory system damage [23]. In a postmortem study, COVID-19 was found to cause direct viral infection of the endothelial cell and widespread endothelial inflammation. Endothelial dysfunction and endothelitis are a principal determinant of microvascular dysfunction by shifting the vascular equilibrium towards more vasoconstriction with subsequent organ ischemia, inflammation with associated tissue edema, and a pro-coagulant state. COVID-19-endothelitis may explain the 
Table 3. Mortality predictors with univariate and multivariate regression models.

\begin{tabular}{|c|c|c|c|c|c|c|}
\hline \multirow[b]{2}{*}{ Covariates } & \multicolumn{3}{|c|}{ Univariate logistic analysis } & \multicolumn{3}{|c|}{ Multivariate logistic analysis } \\
\hline & Odds ratio & $\begin{array}{l}\text { 95\% Confidence } \\
\text { Interval }\end{array}$ & $p$ value & Odds ratio & $\begin{array}{l}\text { 95\% Confidence } \\
\text { Interval }\end{array}$ & $p$ value \\
\hline RegHT vs non-hypertensive & 2.459 & $1.921-3.148$ & $<0.001$ & 1.194 & $0.795-1.794$ & 0.394 \\
\hline ResHT vs non-hypertensive & 3.067 & $1.996-4.714$ & $<0.001$ & 2.013 & $1.085-3.734$ & 0.026 \\
\hline Gender (male) & 1.468 & $1.161-1.857$ & 0.001 & 1.569 & $1.063-2.316$ & 0.023 \\
\hline Oxygen saturation, $\%$ & 0.791 & $0.773-0.810$ & $<0.001$ & 0.822 & $0.799-0.846$ & $<0.001$ \\
\hline Coronary artery disease & 2.448 & $1.832-3.272$ & $<0.001$ & 1.110 & $0.685-1.800$ & 0.671 \\
\hline Congestive heart failure & 4.313 & $2.683-6.933$ & $<0.001$ & 1.206 & $0.520-2.797$ & 0.662 \\
\hline Chronic renal failure & 17.843 & $10.404-30.600$ & $<0.001$ & 3.680 & $1.081-12.523$ & 0.037 \\
\hline Atrial fibrillation & 2.677 & $1.559-4.598$ & 0.001 & 1.039 & $0.434-2.488$ & 0.932 \\
\hline Lymphocyte, $10^{9} / \mathrm{L}$ & 0.277 & $0.210-0.366$ & $<0.001$ & 0.677 & $0.473-0.971$ & 0.034 \\
\hline Aspartate transaminase, IU/L & 1.004 & $1.002-1.007$ & 0.001 & 1.003 & $0.998-1.007$ & 0.211 \\
\hline Alanine transaminase, IU/L & 1.002 & $1.000-1.004$ & 0.084 & 0.997 & $0.992-1.003$ & 0.397 \\
\hline Creatinine, $\mathrm{mg} / \mathrm{dL}$ & 1.760 & $1.574-1.968$ & $<0.001$ & 1.222 & $1.014-1.473$ & 0.035 \\
\hline Lactate dehydrogenase $(\log 10)$, IU/L & 24.564 & $12.403-48.648$ & $<0.001$ & 1.623 & $0.473-5.565$ & 0.441 \\
\hline C-reactive protein $(\log 10), \mathrm{mg} / \mathrm{dL}$ & 6.602 & $4.593-9.489$ & $<0.001$ & 1.035 & $0.613-1.748$ & 0.897 \\
\hline Ferritin $(\log 10), \mathrm{ng} / \mathrm{ml}$ & 2.944 & $2.206-3.929$ & $<0.001$ & 0.869 & $0.525-1.440$ & 0.586 \\
\hline Procalcitonin $(\log 10), \mathrm{ng} / \mathrm{ml}$ & 5.906 & $4.702-7.420$ & $<0.001$ & 2.034 & $1.489-2.779$ & $<0.001$ \\
\hline D-dimer $(\log 10), \mathrm{ng} / \mathrm{ml}$ & 5.814 & $4.342-7.784$ & $<0.001$ & 1.288 & $0.819-2.026$ & 0.274 \\
\hline
\end{tabular}

systemic impaired microcirculatory function in different vascular structures and its clinical damages in COVID-19 patients [24]. In a study, high average systolic BP and systolic BP/diastolic BP variability during hospitalization in hypertensive COVID-19 patients were independently associated with in-hospital mortality, ICU admission, and heart failure [25]. For this reason, the association of microvascular disease that hypertension can cause with poor outcomes in COVID-19 is an important issue [26].

There are no studies in the literature on COVID-19 patients with resistant HT. In our study, there is no clear evidence of how ResHT increases mortality in COVID-19 patients. The coexistence of hypertension and COVID-19 infection was thought to interplay synergistically increase the risk of adverse prognosis compared to normotensive COVID-19 patients [27]. We can think of this situation more in resistant hypertensive COVID-19 patients. We know that microvascular and macrovascular adverse outcomes of ResHT and COVID-19. Both conditions may increase mortality by creating a synergistic effect in patients. The reason for increased mortality in COVID-19 patients with hypertension may be the resistant hypertensive condition. Therefore clinicians should interrogate this condition for each hypertensive patient hospitalized with COVID-19 disease. To encourage this, randomized and larger studies are needed.

\section{LIMITATIONS}

Our study has several limitations. First, due to the retrospective nature of this study and the fact that it was conducted in a single hospital, the interpretation of our findings might be limited by the sample size and selection bias. Second, we cannot clearly say that we completely exclude this "white coat effect" in patients. Although 24-hour ambulatory blood pressure follow-up of patients was performed involving the definition of resistant hypertension, since our study was retrospective, we had no such facility. For this reason, the definition of resistant hypertension in hypertensive patients was made with serial blood pressure measurement results. Third, we know that the frequency of resistant hypertension is higher in obese patients. However, in our study, we do not have enough data on the morphological structure and weight of patients. Therefore we could not include obesity in our study. Considering all these limitations, larger and prospective studies on these patients are needed.

\section{CONCLUSION}

Our study is a mortality study in which we evaluated resistant hypertension in COVID-19 patients. Hypertension is a major comorbidity in hospitalized COVID-19 patients. We found that RegHT or ResHT can be associated with some adverse clinical outcomes in- 
hospital. This condition provides important information about prognosis in the clinical management of patients. According to our study, ResHT was independently associated with a significantly increased risk of in-hospital mortality of COVID-19, while no significant increased risk was observed with RegHT. In other words, the ResHT is more fatal in COVID-19 patients.

\section{Summary}

What is known about topic

- We know that hypertension is a major comorbidity in COVID19. Hypertension is associated with adverse clinical outcomes in COVID-19 patients. But the effect of ResHT on in-hospital mortality is unknown.

What this study adds

- The mortality, ARDS, and need for intensive care rates are higher in patients with hypertension. We can say that resistant hypertension is an independent predictor of mortality, but not for regulated hypertension. Clinicians should examine this condition for each hypertensive patient hospitalized with COVID-19 disease.

\section{REFERENCES}

1. World Health Organization (WHO). Coronavirus disease (COVID-19) outbreak, https://www.who.int/westernpacific/emergencies/covid-19.

2. Grasselli G, Zangrillo A, Zanella A, Antonelli M, Cabrini L, Castelli A. et al. Baseline characteristics and outcomes of 1591 patients infected with SARS-CoV-2 admitted to ICUs of the Lombardy Region, Italy. JAMA. 2020;323:1574-81. https://doi. org/10.1001/jama.2020.5394.

3. Richardson S, Hirsch JS, Narasimhan M, Crawford JM, McGinn T, Davidson KW. et al. Presenting characteristics, comorbidities, and outcomes among 5700 patients hospitalized with COVID-19 in the New York City Area. JAMA. 2020;323:2052-9. https://doi.org/10.1001/jama.2020.6775.

4. Carey RM, Calhoun DA, Bakris GL, Brook RD, Daugherty SL, Himmelfarb CD. et al. Resistant hypertension: detection, evaluation, and management: a scientific statement from the American Heart Association. Hypertension. 2018;72:e53-90. https://doi.org/10.1161/HYP.0000000000000084.

5. Whelton PK, Carey RM, Aronow WS, CaseyJr DE, Collins KJ, Himmelfarb $C D$, et al. 2017 ACC/AHA/AAPA/ABC/ACPM/AGS/APhA/ASH/ASPC/NMA/PCNA Guideline for the prevention, detection, evaluation, and management of high blood pressure in adults: a report of the American College of Cardiology/American Heart Association task force on clinical practice guidelines. Hypertension. 2018;71:e13.

6. Braam B, Taler SJ, Rahman M, Fillaus JA, Greco BA, Forman JP, et al. Recognition and management of resistant hypertension. Clin J Am Soc Nephrol. 2017;12:524

7. Daugherty SL, Powers JD, Magid DJ, Tavel HM, Masoudi FA, Margolis KL. et al. Incidence and prognosis of resistant hypertension in hypertensive patients. Circulation. 2012;125:1635-42. https://doi.org/10.1161/CIRCULATIONAHA.111.068064.

8. Irvin MR, Booth JN, Shimbo D, Lackland DT, Oparil S, Howard G. et al. Apparent treatment-resistant hypertension and risk for stroke, coronary heart disease, and all-cause mortality. J Am Soc Hypertens. 2014;8:405-13. https://doi.org/10.1016/j. jash.2014.03.003.

9. Liang X, Shi L, Wang Y, Xiao W, Duan G, Yang H. et al. The association of hypertension with the severity and mortality of COVID-19 patients: evidence based on adjusted effect estimates. J Infect. 2020;81:e44-7.

10. Republic of Turkey Ministry of Health, COVID-19 guide. https://covid19.saglik.gov. tr/TR-66301/covid-19-rehberi.html.

11. Frank EH Jr. Regression modeling strategies: with applications, to linear models, logistic and ordinal regression, and survival analysis, 2nd ed. Switzerland: Springer International Publishing; 2015.

12. Tanboğa IH, Canpolat U, Çetin EHÖ, Kundi H, Çelik O, Çağlayan $\mathrm{M}$, et al. Development and validation of clinical prediction model to estimate the probability of death in hospitalized patients with COVID-19: Insights from a nationwide database. J Med Virol. 2021 Feb. https://doi.org/10.1002/jmv.26844.

13. Guan WJ, Liang WH, Zhao Y, Liang HR, Chen ZS, Li YM, et al. Comorbidity and its impact on 1590 patients with COVID-19 in China: a nationwide analysis. Eur Respir J. 2020;55:2000547.
14. Rodilla E, Suara A, Jimenez I, Mendizabal A, Pinera-Cantero A, Lorenzo-Hernandez E. et al. Association of hypertension with all-cause mortality among hospitalized patients with COVID-19. J Clin Med. 2020;9:3136. https://doi.org/10.3390/jcm9103136.

15. Yang G, Tan Z, Zhou L, Yang M, Peng L, Liu J. et al. Effects of angiotensin II receptor blockers and ACE (Angiotensin-Converting Enzyme) inhibitors on virus infection, inflammatory status, and clinical outcomes in patients With COVID-19 and hypertension: a single-center retrospective study. Hypertension. 2020;76:51-8. https://doi.org/10.1161/HYPERTENSIONAHA.120.15143.

16. Nicin L, Abplanalp WT, Mellentin H, Kattih B, Tombor L, John D. et al. Cell typespecific expression of the putative SARS-CoV-2 receptor ACE2 in human hearts. Eur Heart J. 2020;41:1804-6. https://doi.org/10.1093/eurheartj/ehaa311.

17. Clark CE, McDonagh STJ, McManus R, Martin U. Covid-19 and hypertension: risks and management. A scientific statement on behalf of the British and Irish Hypertension Society. J Hum Hypertens. 2021;35:304-7. https://doi.org/10.1038/ s41371-020-00451-x.

18. HFSA/ACC/AHA statement addresses concerns re: using RAAS antagonists in COVID-19. Accessed March 29, 2020.

19. Muiesan ML, Salvetti M, Rizzoni D, Paini A, Agabiti-Rosei C, Aggiusti C, et al. Resistant hypertension and target organ damage. Hypertension Res. 2013;36:485-91.

20. Pimenta E, Calhoun DA. Resistant hypertension: incidence, prevalence, and prognosis. Circulation. 2012;125:1594-6.

21. Rizzoni D, Porteri E, Boari GE, De Ciuceis C, Sleiman I, Muiesan ML. et al. Prognostic significance of small-artery structure in hypertension. Circulation. 2003;108:2230-5. https://doi.org/10.1161/01.CIR.0000095031.51492.C5.

22. Schmieder RE, Schmidt BMW, Raff U, Bramlage $P$, Dörfler A, Achenbach S. et al. Cerebral microangiopathy in treatment-resistant hypertension. J Clin Hypertens (Greenwich). 2011;13:582-7. https://doi.org/10.1111/j.1751-7176.2011.00493.x.

23. Becker RC. COVID-19-associated vasculitis and vasculopathy. J Thromb Thrombolysis. 2020;50:499-511. https://doi.org/10.1007/s11239-020-02230-4.

24. Varga Z, Flammer AJ, Steiger $P$, Haberecker $M$, Andermatt $R$, Zinkernagel AS. et al. Endothelial cell infection and endotheliitis in COVID-19. Lancet. 2020;395:1417-8. https://doi.org/10.1016/S0140-6736(20)30937-5.

25. Ran J, Song Y, Zhuang Z, Han L, Zhao S, Cao P, et al. Blood pressure control and adverse outcomes of COVID-19 infection in patients with concomitant hypertension in Wuhan, China, Hypertens Res. 2020 Aug: 1-10. https://doi.org/10.1038/ s41440-020-00541-w.

26. Cook TM. The importance of hypertension as a risk factor for severe illness and mortality in COVID-19. Anaesthesia. 2020;75:962-77. https://doi.org/10.1111/ anae.15103.

27. Lippi G, Wong J, Henry BM. Hypertension in patients with coronavirus disease 2019 (COVID-19): a pooled analysis. Pol Arch Intern Med. 2020;130:304-9. https://doi.org/10.20452/pamw.15272.

\section{ACKNOWLEDGEMENTS}

We would like to thank the Republic of Turkey Ministry of Health, for permission to publish this paper. All of the authors have accepted responsibility for the entire content of this submitted paper and approve its submission.

\section{AUTHOR CONTRIBUTIONS}

$\mathrm{Fl}$ originated the idea of the research. $\mathrm{FI}$ and $\mathrm{MÇ}$ designed the study. $\mathrm{AA}, \mathrm{ÖB}, \mathrm{BA}, \mathrm{U} \mathrm{i}$ IK, ET, MO, and NKÇ collected data. FI, MÇ, and AK analyzed the data. $\mathrm{FI}, \mathrm{MC}$, and EB wrote the paper. AK supervised the study. All authors have contributed considerably to the paper to be published.

\section{COMPETING INTERESTS}

The authors declare no competing interests.

\section{ADDITIONAL INFORMATION}

Supplementary information The online version contains supplementary material available at https://doi.org/10.1038/s41371-021-00591-8.

Correspondence and requests for materials should be addressed to $F$.

Reprints and permission information is available at http://www.nature.com/ reprints

Publisher's note Springer Nature remains neutral with regard to jurisdictional claims in published maps and institutional affiliations. 